\title{
ESTRESSE SALINO EM PLÂNTULAS DE MILHO: PARTE I ANÁLISE DO CRESCIMENTO ${ }^{1}$
}

\author{
André Dias de Azevedo Neto ${ }^{2}$ \& José Nildo Tabosa ${ }^{3}$
}

\begin{abstract}
RESUMO
O trabalho foi conduzido em casa de vegetação, objetivando-se avaliar o efeito do estresse salino sobre o crescimento de cultivares de milho com tolerância diferenciada à salinidade. Foi utilizado um arranjo fatorial 2 x 5 com duas cultivares de milho (P-3051 e BR-5011) e cinco níveis de cloreto de sódio na solução nutritiva $\left(0,25,50,75\right.$ e $\left.100 \mathrm{~mol} \mathrm{~m}^{-3}\right)$. Avaliaram-se a matéria seca (MS) da parte aérea e raízes, razão parte aérea/raiz, área foliar (AF), taxas de crescimento absoluto (TCA), relativo (TCR) e de assimilação líquida (TAL) e razão de área foliar (RAF). Excetuando-se a RAF, o estresse salino afetou as demais variáveis estudadas. A MS da parte aérea e raízes, AF, TCA e TCR, sobressaíram-se como os indicadores que melhor representaram o efeito do estresse salino sobre as plantas. Por outro lado, a razão parte aérea/raiz, TAL e RAF foram as variáveis que melhor expressaram os caracteres de tolerância e sensibilidade nas cultivares analisadas.
\end{abstract}

Palavras-chave: salinidade, área foliar, taxa de crescimento relativo, taxa de assimilação líquida

\section{SALT STRESS IN MAIZE SEEDLINGS: PART I GROWTH ANALYSIS}

\begin{abstract}
The work was performed in the greenhouse, aiming to evaluate the effect of salt stress on maize cultivars differing in salinity tolerance. Data were carried out on $2 \times 5$ factorial arrangement with two maize cultivars (P-3051 and BR-5011) and five sodium chloride levels in nutritive solution $(0,25,50,75$ or $100 \mathrm{~mol} \mathrm{~m}^{-3}$ ). The shoot dry matter, root dry matter, shoot to root ratio, leaf area (LA), absolute growth rate (AGR), relative growth rate (RGR), net assimilation rate (NAR) and leaf area ratio (LAR) were analyzed. The salt stress affected all studied variables, except LAR. The shoot dry matter, root dry matter, LA, AGR and RGR were the best parameters to express the salt stress effect on maize plants. On the other hand, the shoot to root ratio, NAR and the LAR were the best parameters to express differences between cultivars regarding their tolerance or sensitivity to salt stress.
\end{abstract}

Key words: salinity, leaf area, relative growth rate, net assimilation rate

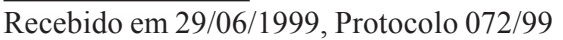

${ }^{1}$ Parte da Dissertação de Mestrado do primeiro autor

${ }^{2}$ MSc. Fisiologia Vegetal, Pesquisador Dep. Química/UFRPE. Rua D. Manoel de Medeiros s/n, Dois Irmãos, Recife, PE. CEP 52171 - 900. Fone: (0xx81) 441 4577, Ramal 355, Fax: (0xx81) 441 4697. E-mail: aazevedo@ipa.br

${ }^{3}$ MSc. Melhoramento Vegetal, Pesquisador IPA, Bolsista CNPq. Av. Gal. San Martin, 1371, Bonji, Recife, PE. CEP 50761 - 000. Fone: (0xx81) 445 2200, Ramal 174, Fax: (0xx81)227 4017.E-mail: tabosa@ipa.br 


\section{INTRODUÇÃO}

O estresse salino representa um dos mais sérios fatores que limitam o crescimento e a produção das culturas, induzindo a modificações morfológicas, estruturais e metabólicas nas plantas superiores (Izzo et al., 1991). Como o milho é considerado uma cultura moderadamente tolerante à salinidade (Richards, 1974; Daker, 1976) sofre, como tal, redução progressiva do crescimento, com o aumento da concentração de sais no meio radicular.

Vários trabalhos reportam os efeitos deletérios do estresse salino sobre o crescimento do milho, independentemente da variável utilizada para esta avaliação (Totawat \& Mehta, 1985; Izzo et al., 1991; Hasaneen et al., 1994 e Saneoka et al., 1995). Há de se ressaltar, entretanto, que as cultivares de milho produzem diferentemente quando sujeitas à salinidade (Hajibagheri et al., 1987; Alberico \& Cramer, 1993; Azevedo Neto, 1997).

Para o estudo dos efeitos ambientais sobre o crescimento dos vegetais, são encontrados, na literatura, vários conceitos e técnicas de análise de crescimento. Assim a interferência do ambiente sobre a produção das culturas pode ser evidenciada pelas alterações no crescimento dos vegetais (Nilwik, 1981). Para mensuração dessas alterações, o acúmulo de matéria seca é, talvez, o parâmetro mais significativo, já que o mesmo é resultante da associação de vários outros componentes (Magalhães, 1985; Coll et al., 1988).

De acordo com Benincasa (1988) a análise de crescimento é um meio acessível e preciso para se avaliar o crescimento e inferir a contribuição de diferentes processos fisiológicos sobre o comportamento vegetal. Além disso essa técnica pode ser de grande valor na avaliação de diferenças intra e interespecíficas das diversas características que definem a capacidade produtiva da planta (Magalhães, 1985).

Por conseguinte, este trabalho teve por objetivo estudar o crescimento de cultivares de milho com tolerância diferenciada à salinidade, quando submetidas a diferentes níveis de cloreto de sódio na solução nutritiva, bem como identificar as variáveis de crescimento que melhor expressem os caracteres de tolerância e sensibilidade.

\section{MATERIAL E MÉTODOS}

O trabalho foi conduzido em casa de vegetação, no Departamento de Química da UFRPE, no período de julho a dezembro de 1995. Foram utilizadas 2 cultivares de milho, sendo uma tolerante (P-3051) e outra sensível (BR-5011) à salinidade, quando comparadas entre si. A escolha dessas cultivares baseou-se nos resultados obtidos por Azevedo Neto (1997) comparando, em condições de salinidade, 29 diferentes materiais indicados para o Estado de Pernambuco. O delineamento experimental utilizado foi o inteiramente casualizado, em um arranjo fatorial entre as duas cultivares e cinco níveis de cloreto de sódio $\left(0,25,50,75\right.$ e $\left.100 \mathrm{~mol} \mathrm{~m}^{-3}\right)$ na solução nutritiva de Hoagland \& Arnon (1950), com 5 repetições. As características das soluções nutritivas utilizadas no experimento (Condutividade Elétrica - CE e Potencial Osmótico $-\psi_{\text {os }}$ ) constam na Tabela 1.
Tabela 1. Características das soluções nutritivas referentes aos tratamentos salinos utilizados no experimento

\begin{tabular}{ccc}
\hline $\begin{array}{c}\text { Níveis de } \mathrm{NaCl} \\
\left(\mathrm{mol} \mathrm{m}^{-3}\right)\end{array}$ & $\begin{array}{c}\text { Condutividade } \\
\text { Elétrica }^{1}\left(\mathrm{dS} \mathrm{m}^{-1}\right)\end{array}$ & $\begin{array}{c}\text { Potencial } \\
\text { Osmótico }^{2}(\mathrm{MPa})\end{array}$ \\
\hline 0 & 2,0 & $-0,07$ \\
25 & 4,6 & $-0,20$ \\
50 & 7,1 & $-0,32$ \\
75 & 9,6 & $-0,43$ \\
100 & 12,0 & $-0,57$ \\
\hline
\end{tabular}

${ }^{2}$ Calculado de acordo com Wyn Jones \& Gorham (1983)

As sementes foram postas para germinar em recipientes do tipo "germbox", forrados com papel mata-borrão e umedecidos em água destilada. Aos 7 dias após a germinação, as plântulas foram transferidas para as respectivas unidades experimentais, as quais constaram de vasos de polietileno com capacidade para 2,5 L. Em cada vaso foi colocada uma plântula, ficando o sistema radicular imerso na solução nutritiva, acrescida ou não de cloreto de sódio, conforme o tratamento. Utilizaram-se minicompressores de ar para promover a aeração da solução nutritiva e, conseqüentemente, a oxigenação do sistema radicular. As soluções nutritivas foram repostas diariamente e renovadas semanalmente, até a coleta do material, a qual foi realizada 21 dias após o início dos tratamentos salinos.

Na coleta do experimento mediu-se a área foliar com medidor de área foliar Li-Cor modelo LI-3000A; em seguida, a parte aérea foi separada das raízes para determinação da matéria seca das partes das plantas. A análise do crescimento foi realizada de acordo com Radford (1967) e Benincasa (1988). A taxa de crescimento absoluto (TCA), taxa de crescimento relativo (TCR), taxa de assimilação líquida (TAL) e razão de área foliar (RAF) foram calculados como segue:

$$
\begin{aligned}
& \mathrm{TCA}=\left(\mathrm{MS}_{\mathrm{f}}-\mathrm{MS}_{\mathrm{i}}\right) / \mathrm{t} \quad\left(\mathrm{g} \mathrm{dia}^{-1}\right) \\
& \mathrm{TCR}=\left(1 / \mathrm{MS}_{\mathrm{f}}\right)\left(\partial \mathrm{MS}_{\mathrm{f}} / \partial \mathrm{t}\right) \quad\left(\mathrm{g} \mathrm{g}^{-1} \mathrm{dia}^{-1}\right) \\
& \mathrm{TAL}=(1 / \mathrm{AF})\left(\partial \mathrm{MS}_{\mathrm{f}} / \partial \mathrm{t}\right) \quad\left(\mathrm{g} \mathrm{dm}^{-2} \mathrm{dia}^{-1}\right) \\
& \mathrm{RAF}=\mathrm{AF} / \mathrm{MS}_{\mathrm{f}} \quad\left(\mathrm{dm}^{2} \mathrm{~g}\right)
\end{aligned}
$$

onde: $\mathrm{MS}_{\mathrm{i}}$ é matéria seca total inicial, $\mathrm{MS}_{\mathrm{f}}$ é matéria seca total final, AF é área foliar e t é o intervalo de tempo entre as amostragens (21 dias).

A determinação da matéria seca inicial foi realizada por meio de estimativa, a partir do peso da matéria fresca de cada plântula e do teor médio de umidade das mesmas, no início dos tratamentos salinos. Os resultados foram analisados estatisticamente e as médias comparadas pelo teste de Tukey, a nível de $5 \%$ de probabilidade, conforme Gomes (1987).

\section{RESULTADOS E DISCUSSÃO}

\section{Produção de matéria seca da parte aérea e raízes}

Observou-se grande similaridade na produção de MS das partes das plantas à medida em que a concentração de cloreto de sódio na solução nutritiva foi aumentada (Tabela 2). A cultivar BR-5011 apresentou redução abrupta dessas variáveis, a partir do nível $50 \mathrm{~mol} \mathrm{~m}^{-3} \mathrm{de} \mathrm{NaCl}$, ao contrário da P-3051, cuja produção de MS declinou suavemente, sendo o efeito significativo apenas no nível mais elevado de salinidade. Conseqüentemente, no nível $100 \mathrm{~mol} \mathrm{~m}^{-3} \mathrm{de} \mathrm{NaCl}$, as cultivares BR-5011 e P-3051 tiveram, respectivamente, a MS da parte aérea reduzida em 74 e $56 \%$ e a 
MS das raízes em 66 e 42\%, quando comparadas com suas testemunhas. Assim a parte aérea mostrou-se mais sensível ao estresse salino que as raízes.

Izzo et al. (1991) relataram que concentrações de 80 e $160 \mathrm{~mol} \mathrm{~m}^{-3}$ de $\mathrm{NaCl}$ na solução nutritiva induziram a uma diminuição na MS da parte aérea das plantas. Por outro lado, as raízes mostraram-se sensíveis apenas às concentrações de $160 \mathrm{~mol} \mathrm{~m}^{-3} \mathrm{de} \mathrm{NaCl}$. Os autores concluíram, ainda, que a maior tolerância das raízes contribuiu para a tolerância das plantas ao estresse salino, semelhantemente ao observado nesse trabalho, cuja cultivar P-3051 apresentou sistema radicular mais tolerante ao estresse salino que a BR-011. Alberico \& Cramer (1993) também observaram redução na MS da parte aérea e raízes de cultivares de milho submetidas a $80 \mathrm{~mol} \mathrm{~m}^{-3} \mathrm{de} \mathrm{NaCl}$ na solução nutritiva, sendo a redução na MS da parte aérea superior à das raízes.

Uma das explicações mais aceitas para a inibição do crescimento pelo sal é o desvio de energia do crescimento para a manutenção, isto é, a redução na MS pode refletir o custo metabólico de energia, associado à adaptação a salinidade e redução no ganho de carbono (Richardson \& McCree, 1985). Aí, pode-se incluir a regulação do transporte e distribuição iônica em vários órgãos e dentro das células, a síntese de solutos orgânicos para a osmorregulação e/ou proteção de macromoléculas, e a manutenção da integridade das membranas. Assim a menor redução no crescimento do genótipo tolerante pode estar associada, entre outros fatores, a um menor custo energético para osmorregulação, o qual pode ser conseguido através da acumulação e da compartimentação de solutos inorgânicos no vacúolo e solutos orgânicos no citoplasma (Tal, 1985).

\section{Razão parte aérea/raiz}

A adição de cloreto de sódio na solução nutritiva reduziu a razão parte aérea/raiz de ambos os genótipos, indicando que o efeito da salinidade foi mais evidente na parte aérea que nas raízes (Tabela 2). Entretanto em termos relativos, verifica-se que a redução foi maior no P-3051 (28\%) que no BR-5011 (22\%) sugerindo, então, que as raízes do primeiro foram menos afetadas pela salinidade. Por outro lado observa-se, comparando-se as

Tabela 2. Produção de matéria seca da parte aérea e raízes, razão parte aérea/raiz e área foliar das cultivares de milho P-3051 (tolerante) e BR-5011 (sensível) 21 dias após o transplantio, em função dos níveis de cloreto de sódio utilizados na solução nutritiva ${ }^{1}$

\begin{tabular}{|c|c|c|c|c|c|}
\hline \multirow{2}{*}{$\begin{array}{l}\text { Cultivares } \\
\text { de Milho }\end{array}$} & \multicolumn{5}{|c|}{ Níveis de $\mathrm{NaCl}\left(\mathrm{mol} \mathrm{m}^{-3}\right)$} \\
\hline & 0 & 25 & 50 & 75 & 100 \\
\hline & \multicolumn{5}{|c|}{ Matéria Seca da Parte Aérea (g planta $\left.{ }^{-1}\right)$} \\
\hline P-3051 & $11,34 \mathrm{Ba}$ & $10,21 \mathrm{Ba}$ & $8,75 \mathrm{Ba}$ & $8,03 \mathrm{Aab}$ & $4,97 \mathrm{Ab}$ \\
\hline \multirow[t]{2}{*}{ BR-5011 } & $13,47 \mathrm{Aa}$ & $12,10 \mathrm{Aa}$ & $11,39 \mathrm{Aa}$ & $5,38 \mathrm{Bb}$ & $3,56 \mathrm{Ab}$ \\
\hline & \multicolumn{5}{|c|}{ Matéria Seca de Raízes (g planta $\left.{ }^{-1}\right)$} \\
\hline P-3051 & $2,90 \mathrm{Aa}$ & $2,73 \mathrm{Aa}$ & $2,43 \mathrm{Aab}$ & $2,45 \mathrm{Aab}$ & $1,68 \mathrm{Ab}$ \\
\hline \multirow[t]{2}{*}{ BR-5011 } & $2,95 \mathrm{Aa}$ & $2,43 \mathrm{Aa}$ & $2,52 \mathrm{Aa}$ & $1,31 \mathrm{Bb}$ & $1,00 \mathrm{Bb}$ \\
\hline & \multicolumn{5}{|c|}{ Razão Parte Aérea/Raiz } \\
\hline P-3051 & $4,06 \mathrm{Ba}$ & $3,73 \mathrm{Bab}$ & $3,63 \mathrm{Bab}$ & $3,41 \mathrm{Bab}$ & $2,94 \mathrm{Bb}$ \\
\hline \multirow[t]{2}{*}{ BR-5011 } & $65 \mathrm{Aa}$ & $5,07 \mathrm{Aa}$ & $4,47 \mathrm{Aab}$ & $4,23 \mathrm{Abc}$ & $3,64 \mathrm{Ac}$ \\
\hline & \multicolumn{5}{|c|}{ Área Foliar $\left(\mathrm{dm}^{2}\right.$ planta $\left.^{-1}\right)$} \\
\hline P-3051 & $25,49 \mathrm{Ba}$ & $22,51 \mathrm{Bab}$ & $19,53 \mathrm{Bab}$ & $18,19 \mathrm{Abc}$ & $11,80 \mathrm{Ac}$ \\
\hline BR-5011 & $32,25 \mathrm{Aa}$ & $29,07 \mathrm{Aa}$ & $27,17 \mathrm{Aa}$ & $12,96 \mathrm{Bb}$ & $8,55 \mathrm{Ab}$ \\
\hline
\end{tabular}

cultivares, que a P-3051 apresentou razão parte aérea/raiz inferior à BR-5011, independentemente do nível de salinidade utilizado, evidenciando maior proporção de raízes em relação à matéria seca total da P-3051, quando comparada com a BR-5011. Desta forma, a razão parte aérea/raiz mostrou ser, para as cultivares estudadas, um parâmetro eficiente na distinção dos caracteres de tolerância e sensibilidade.

Resultados semelhantes foram obtidos por Lewis et al. (1989) ao reportarem reduções de $27 \%$ na razão parte aérea/raiz de plântulas de milho cultivadas em $80 \mathrm{~mol} \mathrm{~m}^{-3} \mathrm{de} \mathrm{NaCl}$, na solução nutritiva. Izzo et al. (1991) também verificaram diminuição na razão parte aérea/raiz de plântulas de milho, com o incremento do estresse salino.

Os dados da literatura sugerem que, em milho, as raízes parecem suportar melhor a salinidade que a parte aérea, fenômeno este que pode estar associado a um ajustamento osmótico mais rápido e a uma perda de turgor mais lenta das raízes, quando comparadas com a parte aérea. Conseqüentemente, o crescimento radicular pode ser menos sensível que o crescimento da parte aérea a uma redução no potencial osmótico (Shalhevet et al., 1995). Desta forma, o maior crescimento do sistema radicular no genótipo P-3051, em relação ao BR-5011, pode ter contribuído para sua tolerância ao estresse salino, em virtude do menor crescimento das partes com elevada capacidade transpirativa (Azevedo Neto et al., 1996b).

\section{Área foliar (AF)}

Analogamente ao observado para a produção de matéria seca, a AF dos genótipos estudados declinou em função dos aumentos nas concentrações de cloreto de sódio na solução nutritiva (Tabela 2). Todavia enquanto a AF da cultivar P-3051 diminuiu lentamente com a elevação do estresse salino, a AF da BR-5011 foi fortemente afetada a partir do nível $50 \mathrm{~mol} \mathrm{~m}^{-3}$ de $\mathrm{NaCl}$. Conseqüentemente, no nível mais elevado de salinidade, ambas, P-3051 e BR-5011, apresentaram reduções de AF equivalentes a 54 e $73 \%$, quando comparadas com suas respectivas testemunhas.

Totawat \& Mehta (1985) trabalhando com genótipos de milho e sorgo, verificaram que a AF de ambas as espécies foi influenciada negativamente pelo estresse salino. Em 12,0 $\mathrm{dS} \mathrm{m}^{-1} \mathrm{de}$ condutividade elétrica, as plantas de milho e sorgo tiveram sua AF reduzida em 46 e $60 \%$, respectivamente. Alberico \& Cramer (1993) observaram que a AF de plântulas de milho foi um excelente indicador do efeito dos tratamentos salinos, já que a mesma foi reduzida em cerca de $45 \%$ com a adição de $80 \mathrm{~mol} \mathrm{~m}^{-3}$ de $\mathrm{NaCl}$ à solução nutritiva. Em adição, Hasaneen et al. (1994) verificaram que o estresse salino reduziu a AF de plantas de milho em 52\%. Recentemente, Saneoka et al. (1995) reportaram redução na AF de plântulas de milho sob estresse salino, tendo os genótipos tolerantes apresentado AF superior aos genótipos sensíveis.

A redução da elongação foliar sob estresse hídrico pode ser um mecanismo de sobrevivência que permite a conservação de água. Contudo não necessariamente é o caso do estresse salino, onde a disponibilidade de água para o crescimento em geral não é limitante, a medida em que o gradiente de potencial hídrico favorece a absorção, em virtude da osmorregulação. Desta forma, a redução na $\mathrm{AF}$, como conseqüência do estresse salino, pode representar a inabilidade das plantas para discriminar entre os estresses hídrico e salino (Binzel et al., 1985) ao invés de um mecanismo de adaptação (Greenway \& Munns, 1980). 
A despeito das considerações acima, a brusca redução da AF observada no genótipo BR-5011 reflete sua maior susceptibilidade aos efeitos do cloreto de sódio na solução nutritiva, em relação ao P-3051.

\section{Taxas de Crescimento Absoluto (TCA) e Relativo (TCR)}

Pode-se verificar, na Tabela 3, que os tratamentos salinos diminuíram significativamente nas duas cultivares estudadas, TCA e TCR. Contudo este efeito foi menos pronunciado na P3051, de maneira que os valores de TCA e TCR, nos níveis 75 e $100 \mathrm{~mol} \mathrm{~m}^{-3} \mathrm{de} \mathrm{NaCl}$, foram significativamente maiores que na BR-5011. Comparando-se a velocidade de crescimento (TCA) e o impulso de crescimento (TCR) do tratamento $100 \mathrm{~mol} \mathrm{~m}^{-3} \mathrm{de}$ $\mathrm{NaCl}$ com os do tratamento $0 \mathrm{~mol} \mathrm{~m}^{-3} \mathrm{de} \mathrm{NaCl}$, eles equivalem, respectivamente, a 46 e $81 \%$ para a cultivar P-3051 e a 27 e $74 \%$, para a BR-5011.

Tabela 3. Taxas de crescimento absoluto, relativo, de assimilação líquida e razão deárea foliar das cultivares de milho P-3051 (tolerante) e BR-5011 (sensível) aos 21 dias após o transplantio, em função dos níveis de cloreto de sódio utilizados na solução nutritiva ${ }^{1}$

\begin{tabular}{|c|c|c|c|c|c|}
\hline \multirow{2}{*}{$\begin{array}{c}\text { Cultivares } \\
\text { de Milho }\end{array}$} & \multicolumn{5}{|c|}{ Níveis de $\mathrm{NaCl}\left(\mathrm{mol} \mathrm{m}^{-3}\right)$} \\
\hline & 0 & 25 & 50 & 75 & 100 \\
\hline & \multicolumn{5}{|c|}{ Taxa de Crescimento Absoluto $\left(\mathrm{g} \mathrm{dia}^{-1}\right)$} \\
\hline P-3051 & $0,666 \mathrm{Aa}$ & $0,605 \mathrm{Aa}$ & $0,520 \mathrm{Ba}$ & $0,485 \mathrm{Ab}$ & $0,305 \mathrm{Ab}$ \\
\hline \multirow[t]{2}{*}{ BR-5011 } & $0,768 \mathrm{Aa}$ & $0,679 \mathrm{Aa}$ & $0,645 \mathrm{Aa}$ & $0,305 \mathrm{Ba}$ & $0,206 \mathrm{Ab}$ \\
\hline & \multicolumn{5}{|c|}{ Taxa de Crescimento Relativo $\left(\mathrm{g} \mathrm{g}^{-1} \mathrm{dia}^{-1}\right)$} \\
\hline P-30 & $0,192 \mathrm{Aa}$ & $0,188 \mathrm{Aa}$ & $0,178 \mathrm{Aab}$ & $0,168 \mathrm{Abc}$ & $0,157 \mathrm{Ac}$ \\
\hline \multirow[t]{2}{*}{ BR-5011 } & $0,193 \mathrm{Aa}$ & $0,190 \mathrm{Aa}$ & $0,172 \mathrm{Ab}$ & $0,152 \mathrm{Bc}$ & $0,142 \mathrm{Bc}$ \\
\hline & \multicolumn{5}{|c|}{ Taxa de Assimilação Líquida $\left(\mathrm{g} \mathrm{dm}^{-2}\right.$ dia $\left.^{-1}\right)$} \\
\hline P-3051 & $0,107 \mathrm{Aa}$ & $0,108 \mathrm{Aa}$ & $0,102 \mathrm{~A}$ & 0,096Aab & $0,088 \mathrm{Ab}$ \\
\hline \multirow[t]{2}{*}{ BR-5011 } & $8 \mathrm{Ba}$ & $0,095 \mathrm{Ba}$ & $0,088 \mathrm{Bab}$ & $0,078 \mathrm{Bb}$ & $0,076 \mathrm{Bb}$ \\
\hline & \multicolumn{5}{|c|}{ Razão de Área Foliar $\left(\mathrm{dm}^{2} \mathrm{~g}^{-1}\right)$} \\
\hline P-3051 & $1,816 \mathrm{Ba}$ & $1,743 \mathrm{Ba}$ & $1,746 \mathrm{Ba}$ & $1,757 \mathrm{Ba}$ & 1,787Aa \\
\hline BR-5011 & $1,965 \mathrm{Aa}$ & $2,012 \mathrm{Aa}$ & $1,954 \mathrm{Aa}$ & 1,943Aa & $1,870 \mathrm{Aa}$ \\
\hline
\end{tabular}

Semelhantemente, Schwarz \& Gale (1984) verificaram que plantas de milho cultivadas em $50 \mathrm{~mol} \mathrm{~m}^{-3} \mathrm{de} \mathrm{NaCl}$ apresentaram valores de TCR equivalentes a $67 \%$ de suas respectivas testemunhas. Efeitos negativos da salinidade sobre a TCR de milho também foram encontrados por Mladenova (1990) e Erdei \& Taleisnik (1993).

Tem-se demonstrado que a TCR é um parâmetro fortemente influenciado pelas concentrações de íons $\mathrm{Na}^{+}$no tecido vegetal. Akita \& Cabuslay (1990) reportaram este efeito em cultivares de arroz submetidas a estresses salinos de 8,0 e $15,0 \mathrm{dS} \mathrm{m}^{-1}$ de condutividade elétrica. Azevedo Neto et al. (1996a) verificaram correlações negativas altamente significativas entre a TCR de plântulas milho e os teores de $\mathrm{Na}^{+}(\mathrm{r}=-0,92)$ nas plantas.

É possível, então, que o crescimento da cultivar BR-5011 tenha sido diminuído devido ao maior desvio de recursos energéticos para sua osmorregulação (Alarcon et al., 1994).

\section{Taxa de Assimilação Líquida (TAL)}

A cultivar BR-5011 sofreu redução significativa da TAL, a partir do nível $75 \mathrm{~mol} \mathrm{~m}^{-3} \mathrm{de} \mathrm{NaCl}$, ao passo que a P-3051 só expressou este efeito no nível $100 \mathrm{~mol} \mathrm{~m}^{-3} \mathrm{de} \mathrm{NaCl}$ (Tabela 3). Desta forma e em termos relativos, a TAL do P-3051 foi reduzida em $18 \% \mathrm{e}$ a do BR-5011 em 23\%, quando as plantas foram submetidas a $100 \mathrm{~mol} \mathrm{~m}^{-3} \mathrm{de} \mathrm{NaCl}$. Por outro lado, comparando-se a TAL das duas cultivares dentro de cada nível de salinidade, ficou evidenciado que a fotossíntese líquida da P-3051 foi invariavelmente superior à do BR-5011, sugerindo que esta variável foi um indicador bastante realístico quanto aos caracteres de tolerância e sensibilidade.

Rogers \& Noble (1992) encontraram que as taxas de expansão foliar de plantas de trevo branco, expostas a $40 \mathrm{~mol} \mathrm{~m}^{-3} \mathrm{de} \mathrm{NaCl}$, foram sensíveis à salinidade; em contraste, as taxas de fotossíntese líquida permaneceram inalteradas, indicando que o estresse salino não foi suficientemente alto para afetar a fotossíntese ou a atividade da clorofila. Em adição, Alarcon et al. (1994) citaram que plantas de tomate sob estresse salino não mostraram alterações significativas da TAL. Estes autores ponderaram que a taxa de expansão celular parece ser afetada mais rapidamente que a taxa fotossintética, em condições de salinidade. Igualmente, verificou-se, neste trabalho, que a produção de matéria seca de ambas as cultivares foi mais afetada pelo estresse salino que a fotossíntese líquida (TAL).

Yeo et al. $(1977,1985)$ observaram que o efeito inibidor da salinização do meio externo na fotossíntese líquida de plantas de arroz foi maior nas folhas velhas que nas novas, e coincidiu com a acumulação de sódio no tecido. Esses dados estão de acordo com os obtidos neste trabalho e também por Akita \& Cabuslay (1990) onde foram observados decréscimos na TAL, a medida em que a concentração de sódio na parte aérea das plantas foi aumentada.

\section{Razão de Área Foliar (RAF)}

$\mathrm{O}$ incremento da salinidade no meio nutritivo não produziu efeito significativo na RAF de ambas as cultivares, indicando que o efeito do estresse salino na $\mathrm{AF}$ foi de mesma intensidade que na produção de MS (Tabela 3). Com relação às cultivares, observou-se que, no geral, a dimensão relativa do aparelho assimilador do P-3051 foi inferior à do BR-5011, evidenciando alta eficiência fotossintética por unidade de área foliar da primeira, mesmo quando cultivada em ausência de salinidade. Desta forma, semelhantemente ao verificado para a razão parte aérea/raiz e TAL, a RAF foi uma variável importante na diferenciação das características de tolerância ou sensibilidade ao estresse salino nas cultivares estudadas. A ausência de diferença significativa entre os genótipos no nível mais elevado de salinidade, pode estar associada a um efeito menor do auto-sombreamento (Benincasa, 1988) no genótipo sensível, como conseqüência do seu crescimento reduzido neste nível de salinidade.

Totawat \& Mehta (1985) encontraram resultados semelhantes com genótipos de milho e sorgo ao verificarem que, independentemente da espécie, a área foliar, a altura e a produção de matéria seca foram maiores nas plantas que exibiram menor RAF. Cultivares com RAF maior apresentam elevada transpiração aumentando, concomitantemente, a demanda de água e a concentração de íons $\mathrm{Na}^{+}$e/ou $\mathrm{Cl}^{-}$na parte aérea. Por conseguinte a participação da RAF na tolerância ao estresse salino pode ser explicada pela superfície transpirativa da planta, em relação à massa de tecido estar diretamente relacionada à demanda de água e ao transporte de íons $\mathrm{Na}^{+}$e/ou $\mathrm{Cl}^{-}$para a parte aérea (Akita \& Cabuslay, 1990). 


\section{CONCLUSÕES}

1. Nas cultivares avaliadas, a salinidade reduz a produção de matéria seca da parte aérea (56 a 74\%), das raízes (42 a 66\%), da razão parte aérea:raiz (22 a 27\%) e da área foliar (54 a 73\%).

2. Os efeitos adversos do estresse salino são também refletidos através da diminuição na TCA (54 a 73\%), TCR (18 a $26 \%$ ) e TAL (18 a 22\%). Em contraste, a RAF é uma variável pouco influenciada pelos tratamentos salinos, em ambas as cultivares estudadas.

3. Os efeitos deletérios da salinidade são efetivamente evidentes acima do nível $50 \mathrm{~mol} \mathrm{~m}^{-3}$ de cloreto de sódio na solução nutritiva $\left(\mathrm{CE}=7 \mathrm{dS} \mathrm{m}^{-1}\right)$.

4. Dentre as variáveis de crescimento avaliadas, a produção de matéria seca da parte aérea e raízes, a AF, a TCA e a TCR, são as variáveis que melhor representam o efeito do estresse salino sobre as plantas. Por outro lado a razão parte aérea/raiz a TAL e a RAF são as que melhor expressam os caracteres de tolerância e sensibilidade nas cultivares analisadas.

\section{REFERÊNCIAS BIBLIOGRÁFICAS}

AKITA, S.; CABUSLAY, G.S. Physiological basis of differential response to salinity in rice cultivars. Plant and Soil, Dordrecht, v.123, p.277-294, 1990.

ALARCON, J.J.; SANCHEZ-BLANCO, M.J.; BOLARIN, M.C.; TORRECILLAS, A. Growth and osmotic adjustment of two tomato cultivars during and after saline stress. Plant and Soil, Dordrecht, v.166, p.75-82, 1994.

ALBERICO, G.J.; CRAMER, G.R. Is the salt tolerance of maize related to sodium exclusion? I. Preliminary screening of seven cultivars. Journal of Plant Nutrition, New York, v.16, p.2289-2303, 1993.

AZEVEDO NETO, A.D. Estudo do crescimento e distribuição de nutrientes em plântulas de milho submetidas ao estresse salino. Recife: UFRPE, 1997. 134p. Dissertação Mestrado

AZEVEDO NETO, A.D.; BEZERRA NETO, E.; BARRETO, L.P.;

TABOSA, J.N. Resposta de cultivares de milho ao estresse salino: II. Correlação entre os teores teciduais de $\mathrm{Cl}^{-}, \mathrm{Na}^{+} \mathrm{e}$ $\mathrm{K}^{+}$com o crescimento. In: CONGRESSO NACIONAL DE MILHO E SORGO, 21, 1996a, Londrina. Resumos... Londrina: IAPAR, 1996a. p.129.

AZEVEDO NETO, A.D.; BEZERRA NETO E.; BARRETO, L.P.; TABOSA, J.N., ANSELMO, O.C.; CAVALCANTI, P.A. Efeito do estresse salino sobre cultivares de milho: I. Produção e alocação de fitomassa. In: CONGRESSO LATINOAMERICANO DA CIÊNCIA DO SOLO, 21, 1996b, Águas de Lindóia. Resumos... Águas de Lindóia: SBCS, 1996b. CD Rom.

BENINCASA, M.M.P. Análise de crescimento de plantas (noções básicas). $1^{\mathrm{a}}$ ed. Jaboticabal, FUNEP, 1988. 42p.

BINZEL, M.L.; HASEGAWA, P.M.; HANDA, A.K.; BRESSAN, R.A. Adaptation of tobacco cells to NaCl. Plant Physiology, Rockville, v.79, p.118-125, 1985.

COLL, J.B.; RODRIGO, G.N.; GARCIA, B.S.; TOMÉS, R.S. Fisiologia vegetal. Madrid: Ediciones Pirámide, 1988. 819p.

DAKER, A. A água na agricultura: Manual de hidráulica agrícola. 5.ed. rev. ampl. Rio de Janeiro: Freitas Bastos, 1976. v.3, $453 p$.
ERDEI, L.; TALEISNIK, E. Changes in water relation parameters under osmotic and salt stresses in maize and sorghum. Physiologia Plantarum, Copenhagen, v.89, p.381-387, 1993.

GOMES, F.P. Curso de estatística experimental. 12.ed. Piracicaba: Nobel, 1987, 430p.

GREENWAY, H.; MUNNS, R. Mechanisms of salt tolerance in nonhalophytes. Annual Review of Plant Physiology, Palto Alto, v.31, p.149-190, 1980.

HAJIBAGHERI, M.A.; HARVEY, D.M.R.; FLOWERS, T.J. Quantitative ion distribution within root cells of salt-sensitive and salt-tolerant maize varieties. New Phytologist, Cambridge, v.105, p.367-379, 1987.

HASANEEN, M.N.A.; EL-SAHT, H.M.; BASSYONI, F.M. Growth, carbohydrates and associated invertase and amylase activities in castor bean and maize as affected by metribuzin and NaCl. Biologia Plantarum, Prague, v.36, p.451-459, 1994.

HOAGLAND, D.R.; ARNON, D.I. The water-cultured method for growing plants without soil. California: California Agricultural Experiment Station, 1950. 32p. Circular no 347

IZZO, R. NAVARI-IZZO, F.; QUARTACCI, F. Growth and mineral absorption in maize seedlings as affected by increasing $\mathrm{NaCl}$ concentrations. Journal of Plant Nutrition, New York, v.14, p.687-699, 1991.

LEWIS, O.A.M.; LEIDI, E.O.; LIPS, S.H. Effect of nitrogen source on growth response to salinity stress in maize and wheat. New Phytolist, Cambridge, v.111, p.155-160, 1989.

MAGALHÃES, A.C.N. Análise quantitativa do crescimento. In: FERRI, M.G. (Coord.). Fisiologia vegetal. 2.ed. rev. atual. São Paulo: Ed. Pedagógica e Universitária, 1985. v.1, cap.8, p.333350.

MLADENOVA, Y.I. Influence of salt stress on primary metabolism of Zea mays L. seedlings of model genotypes. Plant and Soil, Dordrecht, v.123, p.217-222, 1990.

NILWIK, H.J.M. Growth analysis of sweet pepper (Capsicum anuum L.): 2. Interacting effects of irradiance, temperature and plant age in controlled conditions. Annals of Botany, London, v.49, p.137-145, 1981.

RADFORD, P.J. Growth analysis formulae - Their use and abuse. Crop Science, Madison, v.7, p.171-175, 1967.

RICHARDS, L.A. Suelos salinos y sodicos: Diagnostico y rehabilitacion. 6.ed. México: Editorial Limusa, 1974. 172p.

RICHARDSON, S.G.; McCREE, K.J. Carbon balance and water relations of sorghum exposed to salt and water stress. Plant Physiology, Rockville, v.79, p.1015-1020, 1985.

ROGERS, M.E.; NOBLE, C.L. Variation in growth and ion accumulation between two selected populations of Trifolium repens L. differing in salt tolerance. Plant and Soil, Dordrecht, v.146, p.131-136, 1992.

SANEOKA, H.; NAGASAKA, C.; HAHN, D.T.; YANG, W.J.; PREMACHANDRA, G.S.; JOLY, R.J.; RHODES, D. Salt tolerance of glycinebetaine-deficient and-containing maize lines. Plant Physiology, Rockville, v.107, p.631-638, 1995.

SCHWARZ, M.; GALE, J. Growth response to salinity at high levels of carbon dioxide. Journal of Experimental Botany, Oxford, v.35, p.193-196, 1984.

SHALHEVET, J.; HUCK, M.G.; SCHROEDER, B.P. Root and shoot growth responses to salinity in maize and soybean. Agronomy Journal, Madison, v.87, p.512-516, 1995.

TAL, M. Genetics of salt tolerance in higher plants: theoretical and practical considerations. Plant and Soil, Dordrecht, v.89, p.199-226, 1985. 
TOTAWAT, K.L.; MEHTA, A.K. Salt tolerance of maize and sorghum genotypes. Annals of Arid Zone, Jodh Pur, v.24, p.229-236, 1985.

WYN JONES, R.G.; GORHAM, J. Osmoregulation. In: LANGE, D.L.; NOBEL, P.S.; OSMOND, C.B.; ZIEGLER, H. Encyclopedia of plant physiology: Physiological plant ecology III - Response to chemical and biological environment. Berlin: Springer-Verlag, p.35-58, 1983.
YEO, A.R.; CAPORN, S.J.M.; FLOWERS, T.J. The effect of salinity upon photosynthesis in rice (Oryza sativa L.): Gas exchange by individual leaves in relation to their salt content. Journal of Experimental Botany, Oxford, v.36, p.1240-1248, 1985.

YEO, A.R.; KRAMER, D.; LÄUCHLI, A.; GULLASCH, J. Ion distribution in salt-stressed mature Zea mays roots in relation to ultrastructure and retention of sodium. Journal of Experimental Botany, Oxford, v.28, p.17-29, 1977. 